\title{
MOLECULAR DYNAMICS STUDIES OF THIN-FILMS OF Sn ON Cu *
}

R. Ravelo*, J. Aguilar**, M.I. Baskes***

* Department of Physics and Materials Research Institute, University of Texas, El Paso, TX, 79968

** Materials Research Institute, University of Texas, El Paso, TX 79968

*** Materials Reliability Department, Sandia National Laboratories, Livermore, CA, 94551

\section{ABSTRACT}

Using Molecular Dynamics, the evolution dynamics of Sn on the (111) and (100) surfaces of $\mathrm{Cu}$ have been investigated as a function of coverage and temperature. The interaction potentials are described by modified embedded atom method (MEAM) potentials. The calculated diffusion activation energies of $\mathrm{Cu}$ in $\mathrm{Sn}$ and $\mathrm{Sn}$ in $\mathrm{Cu}$ agree reasonably well with experimental values. We find that the structure of the overlayer depends on the morphology of the substrate and remains stable up to temperatures of the order of $75 \%$ of the melting temperature of the substrate at which diffusion of $\mathrm{Sn}$ into the substrate and $\mathrm{Cu}$ atoms onto the overlayer is observed.

\section{INTRODUCTION}

DTTC QUALTTY INSPEOTEFIE

The dynamical behavior of atoms at an interface is expected to be very different from those in the bulk or at a free surface. In many cases, the interdiffusion of a thin metallic overlayer with a metallic substrate has not been characterized and the structure and composition of the interdiffused layers are not known [1]. Experiments of ultrathin-films of $\mathrm{Sn}$ evaporated on a $\mathrm{Cu}(111)$ substrate have reported the formation of a stable two dimensional alloy phase with a $\mathrm{p}(\sqrt{3} \times \sqrt{3})-R 30^{\circ}$ structure [2]. This phase is said to form by rapid dissolution of excess Sn into the bulk. Annealing at temperatures as high as $1000 \mathrm{~K}$ indicated a loss of the Sn concentration at the surface which is said to become lost to the bulk. The diffusion of $\mathrm{Sn}$ into the substrate is surprising because $\mathrm{Sn}$ and $\mathrm{Cu}$ have very different melting points and at the melting point of $\mathrm{Sn}(510 \mathrm{~K})$, diffusion of $\mathrm{Sn}$ into $\mathrm{Cu}$ which occurs via vacancy formation should be negligible when compared to the diffusion of $\mathrm{Cu}$ into the $\mathrm{Sn}$ which occurs via an interstitial mechanism with small activation energies [3]. Low energy electron diffraction (LEED) studies of thin films of $\mathrm{Sn}$ on $\mathrm{Cu}(100)$ have found evidence of formation of a commensurate two-dimensional phase with a structure strongly-dependent on anneal temperature and $\mathrm{Sn}$ concentration [4]. An earlier study of deposition of $\mathrm{Sn}$ on $\mathrm{Cu}(100)$ reported no evidence of alloy formation for depositions up to one monolayer (ML) of Sn [5]. Thus, although the study of thin overlayers on $\mathrm{Sn}$ on $\mathrm{Cu}$ surfaces has helped understand the kinetics and early stages of $\mathrm{Cu}-\mathrm{Sn}$ alloys formation, there remain many questions in regard to the mobility of $\mathrm{Cu}$ and $\mathrm{Sn}$ atoms at the interface. For instance, one should expect that for coverages of less than 1 $\mathrm{ML}$, the diffusion of $\mathrm{Cu}$ atoms onto the $\mathrm{Sn}$ overlayer should be less than the dilute alloy value due to the large reduction in the number of interstitial sites available to the $\mathrm{Cu}$ atoms.

We present here preliminary results of Molecular Dynamics (MD) simulations of Sn overlayers on $\mathrm{Cu}(100)$ and $\mathrm{Cu}(111)$ surfaces. We looked at $\mathrm{Sn}$ coverages of up to $2 \mathrm{ML}$ over a wide temperature range: $500-1300 \mathrm{~K}$. Our initial aim was to investigate the kinetics of Sn-Cu alloy formation and to see whether coverages below $1 \mathrm{ML}$ modify the diffusion of $\mathrm{Cu}$ atoms into the overlayer via the same interstitial mechanism which occurs in bulk. The atomic interactions are described by modified embedded atoms method (MEAM) potentials [6]. The MEAM formalism is a modification of the well-known embedded atom method (EAM) and includes the angular dependence of the electron density in order to describe bond bending forces necessary to model covalent materials. It has been applied successfully to fcc, bcc, hcp [7] and diamond cubic materials and has been shown to

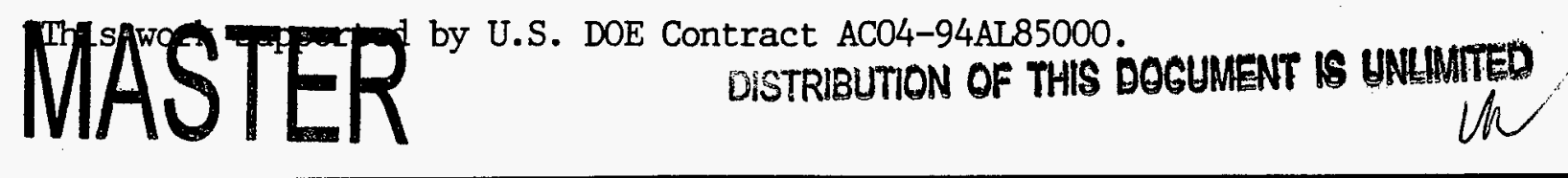




\section{DISCLAIMER}

This report was prepared as an account of work sponsored by an agency of the United States Government. Neither the United States Government nor any agency thereof, nor any of their employees, make any warranty, express or implied, or assumes any legal liability or responsibility for the accuracy, completeness, or usefulness of any information, apparatus, product, or process disclosed, or represents that its use would not infringe privately owned rights. Reference herein to any specific commercial product, process, or service by trade name, trademark, manufacturer, or otherwise does not necessarily constitute or imply its endorsement, recommendation, or favoring by the United States Government or any agency thereof. The views and opinions of authors expressed herein do not necessarily state or reflect those of the United States Government or any agency thereof. 
reproduce quite well the mechanical and thermodynamic properties of the diamond $\alpha, \beta$ and liquid phases of Sn [8]. Using these potentials we calculated the diffusion activation energies of $\mathrm{Sn}$ in $\mathrm{Cu}$ and $\mathrm{Cu}$ in $\mathrm{Sn}$ and made some modifications to the previously published parameters to obtain better agreement with experiment. We will discuss these changes and will present our results on the structure and dynamics of the Sn overlayer with temperature and the correlations between $\mathrm{Cu}$ and $\mathrm{Sn}$ atoms at the interface.

\section{METHODOLOGY AND POTENTIALS}

We utilized slabs of 1800-2000 $\mathrm{Cu}$ atoms with 1 and $2 \mathrm{ML}$ of Sn periodic in the plane of the surface (XY). The Z-direction is defined as normal to the interface. The $\mathrm{Cu}$ side of the slab consisted of 9 layers of which the bottom 3 were kept rigid in order to simulate a semi-infinite slab. The starting configurations were created by placing 3 layers of $\mathrm{Sn}$ in a simple cubic crystal geometry onto the (111) and (100) Cu slabs. These configurations were then annealed at $400 \mathrm{~K}$ for $10 \mathrm{ps}$ in order to obtain equilibrium densities at the interface. From these relaxed slabs, the 1 and $2 \mathrm{ML}$ Sn samples were obtained by removing 2 and 1 layers respectively from the annealed configurations. The resulting slabs were annealed further at 400 and $500 \mathrm{~K}$ for 5 ps. These slabs were then equilibrated at various temperatures in the range $300-1300 \mathrm{~K}$. We monitored the dynamics and structure of the interface by looking at the radial distribution function (RDF), mean squared displacement, velocity-velocity autocorrelation function and trajectories of those atoms in the interface region over 5-10 ps time scales. The melting temperature of MEAM Cu was estimated by simulating the solid-liquid coexisting phase within a $\mathrm{MD}$ formalism [9]. The melting point was found to be between $1200-1400 \mathrm{~K}$, thus in what follows we will use $\mathrm{T}_{m}=1300 \mathrm{~K}$ and express our temperatures as fractions of the substrate melting temperature in order to more readily compare with experimental observations of Sn on other substrates [2].

The $\mathrm{Sn}-\mathrm{Sn}, \mathrm{Cu}-\mathrm{Sn}$ and $\mathrm{Sn}-\mathrm{Sn}$ interactions are described by MEAM potentials. The $\mathrm{Cu}-\mathrm{Sn}$ MEAM model and fitting procedure have been reported in Ref. 10 and will not be repeated here. The $\mathrm{Sn}-\mathrm{Sn}$ interaction parameters were chosen from Ref. 8, while the $\mathrm{Cu}-\mathrm{Cu}$ and $\mathrm{Cu}-\mathrm{Sn}$ parameters were those published in Ref. 10. Angular screening was implemented using the method detailed in Ref. 11 with $\mathrm{C}_{\min }=0.8, \mathrm{C}_{\max }=2.8$ for $\mathrm{Sn}-\mathrm{Sn}, \mathrm{C}_{\min }=2.0, \mathrm{C}_{\max }=2.8$ for $\mathrm{Cu}-\mathrm{Cu}$. For the $\mathrm{Cu}-\mathrm{Sn}$ interactions we modified the parameter $\mathrm{C}_{\min }$ which controls angular screening in MEAM from those used in Ref. 10 in order to optimize the migration energy of $\mathrm{Sn}$ in $\mathrm{Cu}$ and $\mathrm{Cu}$ in $\mathrm{Sn}$ since those quantities are crucial to alloy formation. The activation energy calculation of $\mathrm{Sn}$ in $\mathrm{Cu}$ was carried out employing the 5 frequency method [16] with quasi-static MD. The diffusion activation energies of $\mathrm{Cu}$ atoms in a $\mathrm{Sn}$ matrix were calculated by placing a $\mathrm{Cu}$ atom in various interstitial sites and displacing it with quasi-static MD to adjacent interstitial sites. The path of the $\mathrm{Cu}$ atoms in the direction perpendicular to the c-axis, follow a random-walk motion consisted with what is found experimentally [17]. We found that the diffusion in the parallel direction to the c-axis ( $\beta$-Sn structure) is much lower than the diffusion in the perpendicular direction for the range of $\mathrm{C}_{\min }$ values studied. This is also consisted with experimental results [17]. From these studies we selected a value of 0.8 for $\mathrm{C}_{\min }$ in the $\mathrm{Cu}$-Sn interactions. Results of these calculations are presented in Table I. Agreement with experimental values is fairly good with the notable exception of the vacancy formation energy of $\mathrm{Sn}$ and the activation energy of diffusion for $\mathrm{Cu}$ in $\mathrm{Sn}$ in the direction perpendicular to the c-axis. Both values are overestimated. 


\begin{tabular}{|c|c|c|}
\hline PROPERTY & Theory & Experiment \\
\hline $\mathrm{E}_{1 V}^{f}(\mathrm{Cu})$ & 1.17 & $1.18(\mathrm{a})$ \\
$\mathrm{E}_{1 V}^{m}(\mathrm{Cu})$ & 1.08 & $0.71(\mathrm{a})$ \\
$\mathrm{E}_{1 V}^{f}(\mathrm{Sn})$ & 0.88 & $0.51(\mathrm{~b})$ \\
$\mathrm{E}_{1 V}^{m}(\mathrm{Sn})$ & 0.30 & $0.35(\mathrm{c})$ \\
$\mathrm{Q}_{C u \rightarrow S n}$ (in plane) & $1.10(0.62)$ & $0.34(\mathrm{~d})$ \\
$\mathrm{Q}_{C u \rightarrow S n}$ (in c-direction) & $0.11(0.17)$ & $0.17(\mathrm{~d})$ \\
$\mathrm{Q}_{S n \rightarrow C u}$ & $2.03(2.03)$ & $1.95(\mathrm{e})$ \\
\hline
\end{tabular}

TABLE I. Comparison of diffusion activation energies in $\mathrm{Cu}$ and $\mathrm{Sn}$. All energies are in $\mathrm{eV}$. Relaxed vacancy formation energy $\left(\mathrm{E}_{1 v}^{f}\right)$, vacancy migration energy $\mathrm{E}_{1 V}^{m}$, activation energy of interstitial impurity diffusion of $\mathrm{Cu}$ in $\mathrm{Sn}\left(\mathrm{Q}_{C u \rightarrow S n}\right)$ and of $\mathrm{Sn}$ in $\mathrm{Cu}\left(\mathrm{Q}_{S n \rightarrow C u}\right)$. Values in parentheses for $\mathrm{C}_{\text {min }}=0.8$, others are for $\mathrm{C}_{\min }=2.0$. The diffusion of $\mathrm{Sn}$ in $\mathrm{Cu}$ is through a vacancy mechanism while that of $\mathrm{Cu}$ in $\mathrm{Sn}$ is through an interstitial mechanism. The in-plane direction is perpendicular to the $c$-axis of the $\beta$-tin structure. (a) Ref. 12, (b) Ref. 13, (c) Ref. 14, (d) Ref. (3), (e) Ref. 15.

\section{RESULTS}

We carried out simulations with 1 and $2 \mathrm{ML}$ on $\mathrm{Sn}$ on $\mathrm{Cu}(111)$ and $\mathrm{C}(100)$ over a temperature range $300-1300 \mathrm{~K}$. Our results can be summarized as follows:

1) No melting of the Sn overlayer was observed at any of the sampled temperatures.

2) On both surfaces (111) and (100), Sn seems to form a very stable, ordered structure.

3) No Cu-rich phases are observed and most of the Sn remains on the surface.

4) No significant diffusion of $S n$ into the substrate is observed below temperatures of $0.7 T_{m}$

5) Diffusion of $\mathrm{Cu}$ into the Sn overlayer is observed at lower temperatures for the $\mathrm{Cu}(111)$ than the $\mathrm{Cu}(100$ surfaces.

6) The structure of the $\mathrm{Sn}$ interfacial layer was found to be the same for both 1 and $2 \mathrm{ML}$ coverages.

Figure 1 shows the planar 2-dimensional radial distribution function (RDF) of the Sn overlayer in contact with the substrate at $0.85 \mathrm{~T}_{m}$, together with the RDF of the outermost $\mathrm{Cu}$ layer (at the interface) for both $\mathrm{Sn} / \mathrm{Cu}(111)$ and $\mathrm{Sn} / \mathrm{Cu}(100)$ with $1 \mathrm{ML}$ coverage. The RDF curves are obtained by averaging over 5 ps. From the RDFs, the structure of the Sn layer on both substrates is almost identical. The first, second and third neighbor distance between $\mathrm{Sn}-\mathrm{Sn}$ atoms is approximately 3.2, 6.4 and 9.6 Arespectively on both surfaces which represents distances in the ratio 1:2:3. The sharpness of the peaks indicates that the structure remains very ordered at high temperatures. Very little difference was seen for the interfacial layer between 1 and $2 \mathrm{ML}$ coverages. 

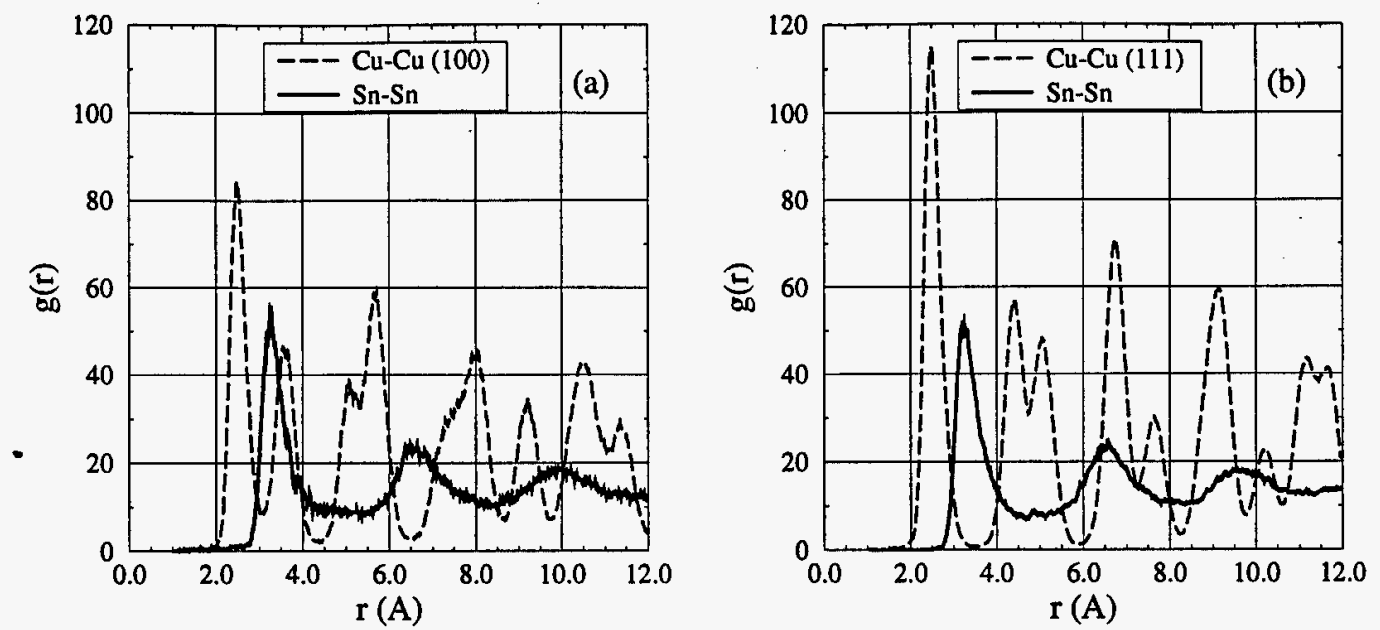

FIG. 1. Two-dimensional (2D) radial distribution function (RDF) of Sn overlayer and first outermost $\mathrm{Cu}$ layer at $0.85 \mathrm{~T}_{m}$ (a) $\mathrm{Sn} / \mathrm{Cu}(100) 1 \mathrm{ML}$ coverage. (b) $\mathrm{Sn} / \mathrm{Cu}(111) 1 \mathrm{ML}$ coverage. The plotted RDF represent averages over $5 p s$. The Sn exhibits 3 sharp peaks while the Cu shows peaks corresponding to the appropriate initial structure.

At temperatures below $0.75 \mathrm{~T}_{m}$ the structure of the Sn overlayer on both $\mathrm{Cu}(111)$ and $\mathrm{Cu}(100)$ is squared with 4-fold symmetry. Figure 2 show a comparison between RDF of $\mathrm{Sn}$ on $\mathrm{Cu}(100)$ (1ML coverage) at two temperatures: $0.70 \mathrm{~T}_{m}$ and $0.85 \mathrm{~T}_{m}$. The 4-fold symmetry of the lower temperature phase can clearly be seen from the RDF.

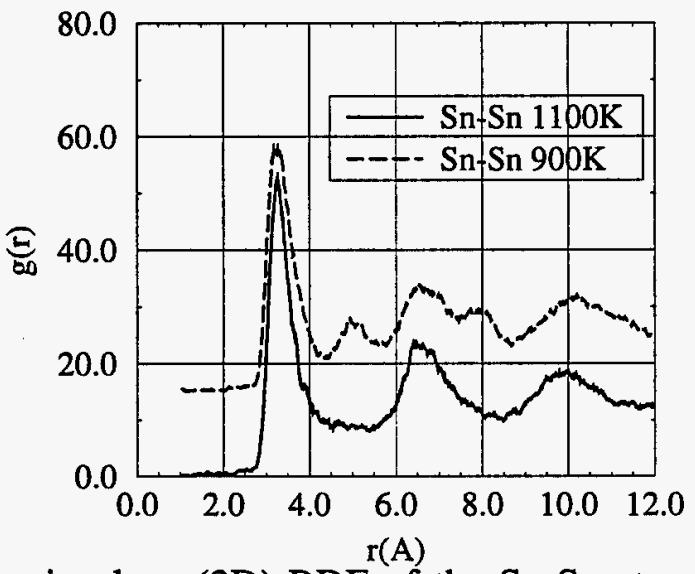

FIG 2. Comparison of the in-plane (2D) RDF of the $\mathrm{Sn}-\mathrm{Sn}$ atoms on $\mathrm{Cu}(100)$ (1 ML) at two different temperatures. The structure at $900 \mathrm{~K}\left(0.70 \mathrm{~T}_{m}\right)$ is a distorted square structure with distances in the ratio: $1: 1.414: 2: 2.44$, while the one at $1100 \mathrm{~K}\left(0.85 \mathrm{~T}_{m}\right)$ has distances in the ratio $1: 2: 3$. The RDF at $900 \mathrm{~K}$ has been displaced vertically for clarity.

More detail of the structure of the overlayer at $0.85 \mathrm{~T}_{m}$ is provided by the atomic trajectories. In Figure 3 we show the motion of the atoms on the surface layer over a 5 ps time period. The structure appears to contain regions of squares and hexagons. It is interesting to see that such a complex structure leads to the simple RDFs shown in Figure 1. We are currently looking more carefully at these structures. The atoms trajectories clearly show that the motion is more vibrational than diffusional. The root mean squared (RMS) motion of the $\mathrm{Sn}$ atoms on the overlayer is about the same as the $\mathrm{Cu}$ atoms in the outermost bilayer. Diffusive motion in the Z-direction is not 

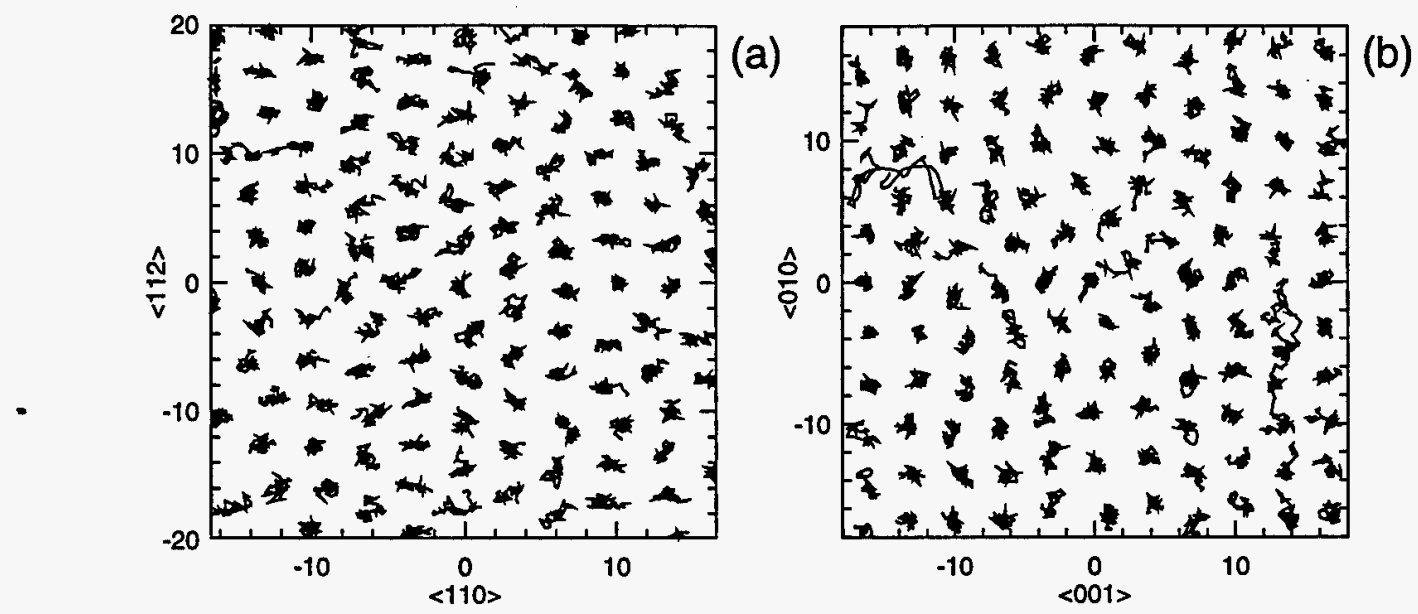

FIG. 3. Top view (XY) of the trajectories of $1 \mathrm{ML}$ of Sn atoms on the (111) (a) and (100) (b) surfaces of $\mathrm{Cu}$ at $0.85 \mathrm{~T}_{m}$. The circles in (a) indicate $\mathrm{Cu}$ atoms. Regions of 4-fold and 6-fold symmetry are seen.

observed until temperatures above $0.75 \mathrm{~T}_{m}$. This temperature is much higher than recent experiment results which indicate that a stable alloy phase does not form on $\mathrm{Cu}(111)$ for annealing temperatures below $0.42 \mathrm{~T}_{m}$ [2]. In Figure 4 we show the temperature dependence of the diffusion of the $\mathrm{Sn}$ atoms in the direction perpendicular to the surface (Z-direction). No surface evaporation is taking place at these temperatures $(700-1300 \mathrm{~K})$, thus this indicates the $\mathrm{Sn}$ atoms are mostly diffusing into the substrate.

Although, it has not been presented here, modification of the screening parameters of $\mathrm{Cu}-\mathrm{Cu}$ potentials which result in a lower melting point show alloy formation at much lower temperatures. This might indicate that the vibrations at the surface (RMS motion) might place a crucial role in the diffusion and alloy formation at the $\mathrm{Cu}-\mathrm{Sn}$ interface

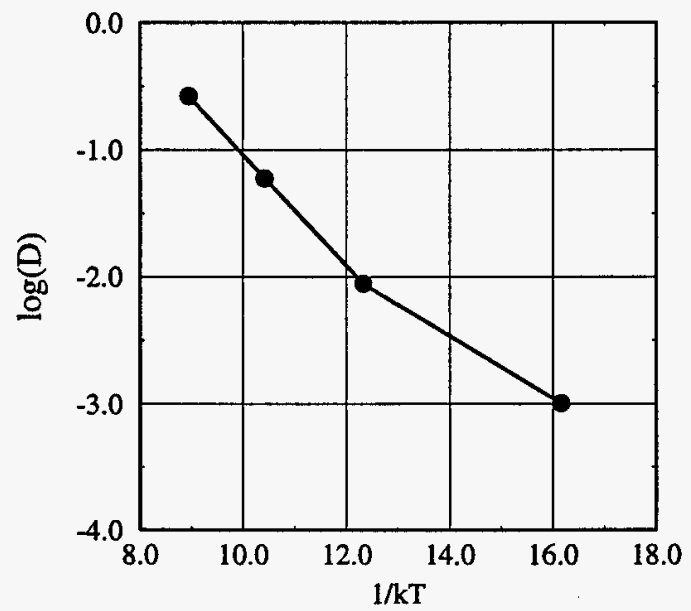

FIG 4. Diffusion of Sn atoms in the direction perpendicular to the surface (Z-direction). The activation energy estimated from the slope at high temperatures is $\mathrm{Q}=0.44 \mathrm{eV}$. 


\section{CONCLUSIONS}

We have calculated the activation energies of diffusion of $\mathrm{Cu}$ in $\mathrm{Sn}$ and $\mathrm{Sn}$ in $\mathrm{Cu}$ (dilute cases) employing a MEAM interaction model of the Cu-Sn system. We find fairly good agreement with experimental values with the notable exception of the diffusion of $\mathrm{Cu}$ in $\mathrm{Sn}$ in the direction perpendicular to the c-axis where we predict a value almost twice as large as the experimental value. We carried out Molecular Dynamics simulations of thin Sn overlayers (1-2 ML thick) on the (111) and (100) surfaces of Cu over a wide temperature range (300-1300 K). We find the Sn forms a very stable incommensurate structure which appears to be the same for both surfaces. This structure remains ordered at high temperatures $(1100-1300 \mathrm{~K})$. We find no significant diffusion of $\mathrm{Cu}$ into the $\mathrm{Sn}$ overlayer or $\mathrm{Sn}$ into the substrate at temperatures below $0.70 \mathrm{~T}_{m}$.

\section{REFERENCES}

[1 ] C.T. Campbell, Annu. Rev. Phys. Chem. 41, p. 775 (1990).

[2 ] S. H. Overbury and Yi-sha Ku, Phys. Rev. B 46, p. 7868 (1992).

[3 ] B.F. Dyson, T.R. Anthony and D. Turnbull, J. Appl. Phys. 38, p. 3408 (1967).

[4 ] F. Abel, C. Cohen, J.A. Davies, J. Moulin and D. Schmaus, Appl. Surf. Sci. 44, pp. 17-27 (1990).

[5 ] G. Argile and G.E. Rhead, Surf. Sci. 135, p. 18 (1983).

[6 ] M.I. Baskes, Phys. Rev. B 46, p. 2727 (1992) and references therein.

[7 ] M.I. Baskes and R.A. Johnson, Modeling Simul. Mater. Sci. Eng. 2, p. 147 (1994).

[8 ] R. Ravelo and M. Baskes, Phys. Rev. Lett. 79, p. 2482 (1997).

[9 ] J.R. Morris, C.Z. Wang, K.M. Ho and C.T. Chan, Phys. Rev. B 49, p. 3109 (1994) and references therein.

[10 ] R. Ravelo and M. Baskes in Thermodynamics and Kinetics of Phase Transformations, edited by J.S. Im, A.L. Greer, B. Park and G.B. Stephenson (Mater. Res. Soc. Proc. 398, Pittsburgh, PA 1996), p. 287.

[11 ] M.I. Baskes, J.E. Angelo and C.L.Bisson, Modeling Simul. Mater. Sci. Eng. 2, 505 (1994).

[12 ] R.W. Balluffi J. Nucl. Mater. 69/70, p. 240 (1978).

[13 ] N. Shah and A.L Catz, Phys. Rev. B 30, p. 2498 (1984).

[14 ] J. Mcllwain et al., Radiation Effects 24, p. 19 (1975).

[15 ] A.D. Le Claire, J. Nucl. Mater. 69/70, p. 70 (1978).

[16 ] A.D. Le Claire, Phil. Mag. 7, p 141 (1962).

[17 ] T.R. Anthony and D. Turnbull, Phys. Rev. 151, p 459 (1966). 


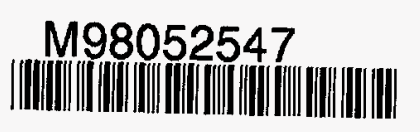

Report Number (14) SAND $-98-8475 \mathrm{C}$
CONF-971201--

Subl. Date (11) $\frac{199803}{\text { Dofonsor Code (18) }}$
JC Category (19) 